\title{
Landscape analysis for multi-hazard prevention in Orco and Soana valleys, Northwest Italy
}

\author{
L. Turconi ${ }^{1}$, D. Tropeano ${ }^{1}$, G. Savio ${ }^{2}$, S. K. De ${ }^{3}$, and P. J. Mason ${ }^{4}$ \\ ${ }^{1}$ Consiglio Nazionale delle Ricerche, Istituto per la Protezione Idrogeologica, CNR-IRPI UOS Torino, Strada delle Cacce 73, \\ 10135 Turin, Italy \\ ${ }^{2}$ CNR-IRPI UOS Torino, Strada delle Cacce 73, 10135 Turin, Italy \\ ${ }^{3}$ Department of Geography, North-Eastern Hill University, NEHU Campus, Shillong, 793022, Meghalaya, India \\ ${ }^{4}$ Imperial College, Department of Earth Science and Engineering, London, Department of Earth Science \& Engineering - \\ Royal School of Mines, Imperial College, Prince Consort Road, London, SW7 2AZ, UK
}

Correspondence to: S. K. De (desunil@yahoo.com)

Received: 7 December 2014 - Published in Nat. Hazards Earth Syst. Sci. Discuss.: 2 April 2015

Revised: 18 June 2015 - Accepted: 19 August 2015 - Published: 8 September 2015

\begin{abstract}
The study area $\left(600 \mathrm{~km}^{2}\right)$, consisting of Orco and Soana valleys in the Western Italian Alps, experienced different types of natural hazards, typical of the whole Alpine environment. Some of the authors have been requested to draw a civil protection plan for such mountainous regions. This offered the special opportunity (1) to draw a lot of unpublished historical data, dating back several centuries mostly concerning natural hazard processes and related damages, (2) to develop original detailed geo-morphological studies in a region still poorly known, (3) to prepare detailed thematic maps illustrating landscape components related to natural conditions and hazards, (4) to thoroughly check present-day situations in the area compared to the effects of past events and (5) to find adequate natural hazard scenarios for all sites exposed to risk. The method of work has been essentially to compare archival findings with field evidence in order to assess natural hazard processes, their occurrence and magnitude, and to arrange all such elements in a database for GISsupported thematic maps. Several types of natural hazards, such as landslides, rockfalls, debris flows, stream floods and snow avalanches cause huge damage to lives and properties (housings, roads, tourist sites). We aim to obtain newly acquired knowledge in this large, still poorly understood area as well as develop easy-to-interpret products such as natural risk maps.
\end{abstract}

\section{Introduction}

Several physical processes of the Alpine environment can be considered dangerous to human lives and their properties (e.g. torrential floods, landslides, snow avalanches, wildfire, earthquakes) and they are commonly referred to as "natural hazards". Those hazards have been investigated and mapped with a view to constructing a GIS database for the widest possible range of events expected in the valleys already mentioned. The Orco and Soana valleys are a part of the oldest natural park in Italy (Gran Paradiso National Park) which attracts several thousand tourists every year. However they possess a long history of instability and have incurred hundreds of casualties and extensive damage by avalanches, rockfalls, soil slips, debris flows and flooding. A rockfall recently (May 2013) $\left(\sim 250 \mathrm{~m}^{3}\right)$ occurred in the vicinity of a settled area (Locana) which has once more confirmed the sensitivity of the territory. The geomorphological evolution of the area can be visualized through the gigantic landslide systems (gravitational slope deformations), which have been triggered by post-glacial remodelling. The aim of the present study is the following: (1) ameliorating knowledge, both on a historical basis and through detailed on-site investigations, of natural hazards affecting a mountainous district in the Orco and Soana Valleys (Western Italian Alps, Fig. 1); (2) to collect any kind of information about physiography, geo-morphology, land use and especially unstable elements in the landscape, in order to prepare informatics tools to ar- 


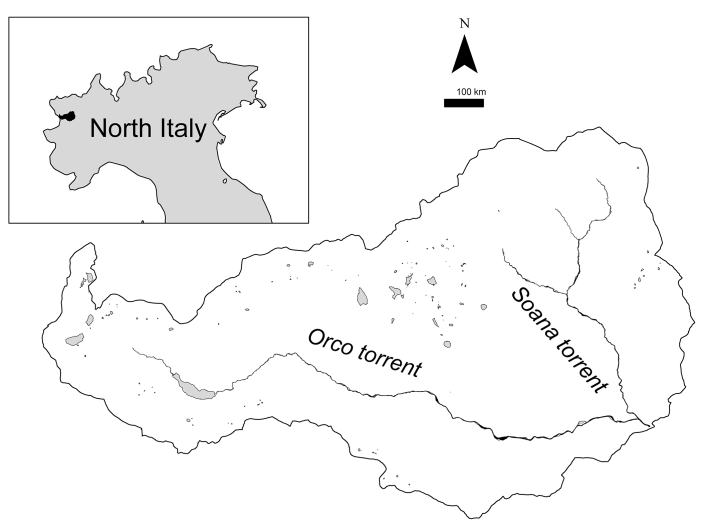

Figure 1. Sketch map of the study area (with main torrents and lakes).

range a civil protection plan for communities forming part of the valleys above.

Forest management in the Orco and Soana Valleys began in the 1900s, even on slopes which are difficult to manage and unsuitable for rapid root establishment. On 7 September 1925, the National Forestry Corporation began a general restoration programme to prevent slope degradation and flooding in several sub-catchments of the region. Such work continued up to and after the Second World War, but ceased in the early 1970s (according to CNR-IRPI archives). For example, the Rio Frera catchment, which was widely populated by larches until a half century ago, still appears in fairly good condition with regard to plant health, in spite of wildfire damage (Fig. 2).

In order to know natural sources of danger and prevent future risks, local communities in the aforementioned valleys have decided to develop a civil protection plan (CPP). Some of the present authors have, thus, been involved in carrying out studies on past and present natural hazards and preparing hazard maps on behalf of the CNR-IRPI Institute. From such a study it has been found that until today about $85 \mathrm{~km}^{2}$ (about $15 \%$ of territory) has been affected by large, deep-seated landslides, involving up to several millions $\mathrm{m}^{3}$ each and about $19 \mathrm{~km}^{2}$ is affected by shallow slides, which are often part of larger slope collapses. Field investigations of stream deposits (geomorphological, stratigraphical and dendro-chronological), supported by historical records, have revealed that almost the entire stream network is prone to debris flows, even in quiescent conditions. In some cases, channels are insufficient to contain the maximum discharge capacity. Like for all kinds of geologic and geomorphological hazard, attention has also been paid to the wildfire hazard, for which an algorithm was developed specifically to highlight the hazard-prone areas; forest cover, being somewhat protective against some gravity-driven accidents (e.g. snow avalanches, rockfalls), when fire-destroyed of course it loses efficiency. In addition, the troublesome issue of coping with natural hazard in an area, where poten-

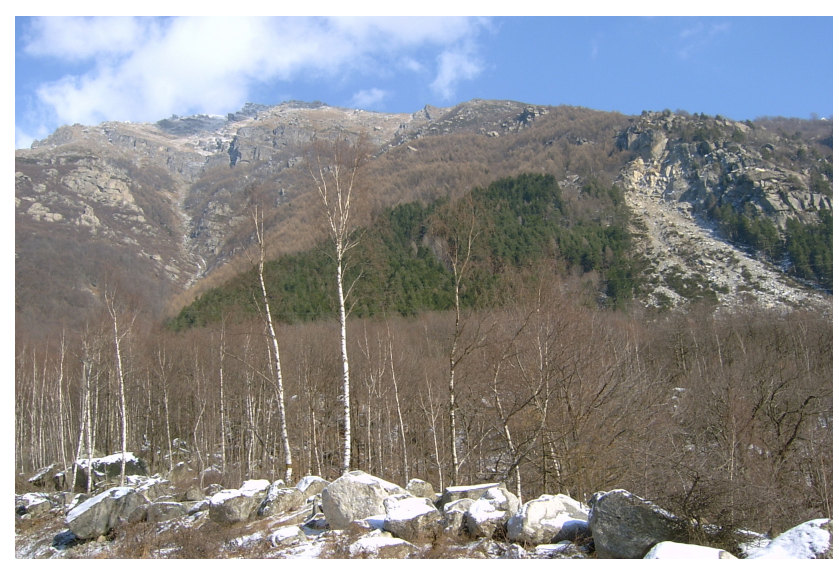

Figure 2. Frontal view of a minor catchment left to the Orco stream in which slope instability processes can be seen towards the right; these have been re-activated in October 2000. In the foreground, mountain birches can be seen, on the left side of the catchment, in a 75-year-old reforested area (photo 25 February 2005).

tial hazard and sustainable development are perennially interacting, have been raised through the comparison of past events and past protection works; all information has been collected from the archival documents (e.g. technical relations, pictures) of several technical bodies. Since the early 1970s the CNR-IRPI was involved in a careful search for old documents throughout northern Italy, mainly in public technical offices, libraries, in order to build a database for natural hazards. Documents relating to the area studied here were integrated with other sources found in local communities. Taking into account the potential for tourism in a large portion of the area, the entire road network has also been mapped according to hazards. The work is concerned with the analysis of relevant physiographic characteristics of the landscape having extremely variable topography and geomorphological processes. Thousands of data (physiography, geology, landslide-debris flow-flood events, snow avalanche, wildfire) as well as digital maps (involving overlay and comparison of several GIS layers) have been analysed and cross-correlated to find out the details of the natural hazard events. Thus, the present area has been selected for such multi-hazard research in which several natural processes have been investigated, concerning their damaging effects on exposed elements over the land. Due to hazardous events at least 250 deaths have been recorded in the area up to now.

\section{The study area}

The Orco and Soana Valleys of Turin Province cover an area of about $618 \mathrm{~km}^{2}$ and comprise 12 communes inhabited by 6000 persons, rising up to about 10000 in the summer. Most of the people live concentrated in vicinity of the major watercourses, along which the most destructive natural events took place historically. The area is bounded by the re- 
gional Piemonte and/or Aosta border and by the NW Italy and SE France border (Fig. 1). The highest peak of the Gran Paradiso massif reaches $4061 \mathrm{~m}$ a.s.l. (above sea level) and is surrounded by glaciers, about $10 \mathrm{~km}^{2}$ in extent. The area is sub-divided into numerous sub-catchments, but in the whole only 50 minor streams strongly influence the torrential activity of the main stream.

Meteorological measurements have been extremely variable between recording stations because of varying local topography and elevation. During winter air temperature fluctuates between strongly positive and negative values; the average extreme ranges between 22.6 and $-6.2^{\circ} \mathrm{C}$ (Mercalli and Cat Berro, 2005). These fluctuating temperatures, also inducing freezing-thawing cycles, contribute to the physical weathering of rocks and thereby to the delivery of debris and other degradational slope processes.

Geologically, the area is dominated by the Upper Pennidic unit of the Gran Paradiso nappe, a unit mainly composed of coarse-textured gneiss and para-schist. Gneissic rocks are the framework of the massif, from where the highest peaks and the water divide between Orco and Aosta Valley draw their origin. The Gran Paradiso nappe consists of tectonic elements of the Dominio Piemontese, which are mainly of marine origin. The lithologies in these units possess strong contrasting competencies that are reflected in their morphological features. Ophiolite masses and calcareous-dolomitic elements appear as the more resistant units, whereas the calc-schists are less resistant and more prone to erosion. To the northwest of the Gran Paradiso massif, internal Pennidic structural units of the Gran San Bernardo unit form the Valsavarenche-Grand Nomenon massif, which is composed of grano-dioritic gneiss and granite. The protoliths consist of Permian magmatic bodies and their surrounding "country" rocks, i.e. Permo-Carboniferous poli-metamorphic schists. The Pennidic units outcropping in this area overlie the Dominio Piemontese units and the Gran San Bernardo unit appears to be folded and back-thrusted on calc-schist.

Generally, the study area is characterized by typical Ushaped glaciated valleys, molded during the Pleistocene and preserved above $2000 \mathrm{~m}$, where the fluvial Holocene degradational processes (slope instability and stream activity) have been less destructive. The present-day morphology causes the super-position and inter-digitations of deposits produced by glaciations, slope instability and fluvial erosion over the course of time. The glacial deposits are usually found at the heads of main and second-order river incisions, and on the flanks of the minor "suspended" valleys at mid-high elevations (above $1500 \mathrm{~m}$ ). They consist of pebbles and boulders in a sandy matrix and are prone to slope collapses. The transition zone between the very steep slopes and the valley bottoms is often marked by large but discontinuous talus. On the flanks and the bottom of recently glaciated valley heads, typically striated and smoothed surfaces are appearing. Other glacial features, e.g. cirques, are frequent and occasionally bear small lakes, which are generally not yet filled with debris.

Freezing-thawing and persistent snow cover may often lead to rock stream and solifluction processes, which typically produce lobate accretionary deposits. These are usually located just above the treeline and carry the material gradually downward by meltwater. Couloirs (preferential paths for avalanches) are common and usually develop along the lines of structural weaknesses, which may be enlarged by erosional (mainly torrential) processes. Deep-seated large gravitational bodies, typically but not exclusively gravitational slope deformations (GSD), are revealed by scarp slopes (often tectonically induced) and by the presence of discontinuities. The lowering (by undercutting) of valley bottoms and solicitations on slopes by glacial activity, stream erosion, climatic history, as well by tectonic stresses and very rarely seismic shocks can be considered as the preparatory causes of gravitational processes.

The stream network (density, alignment and development) is clearly controlled by structural discontinuities (faults and joints) and the average drainage density is usually about $3 \mathrm{~km} \mathrm{~km}^{-2}$. It occasionally exceeds to $4 \mathrm{~km} \mathrm{~km}^{-2}$. In some cases neotectonic fault systems also affect the Quaternary deposits (Malaroda, 2004).

\section{Methodology}

The work mainly consisted of two aspects: search of data and cartographic analysis. The preparatory work made by authors involved essentially (1) historical research in CNR-IRPI's archives and local communities archives about gravity-driven and streamflow processes and effects (a lot of research data issued from documents and bibliography), (2) field geomorphological surveys and (3) interpretation of aerial photographs at a scale of $1: 15000$, which have been acquired in 8-year intervals over a period of 50 years (1954 to 2005). Based on several on-site recognitions, also suggested by old archival reports dealing with past destructive landslide or debris flow and flood events, numerous unstable sites or strips of land have been identified, both on slopes and across the drainage network. Then various data analysis approaches have been adopted in the present study (both sequential and collective).

During the course of the project, hazard scenarios for avalanches, landslides and stream erosion have been developed. Continuous comparisons among those events have been done with the help of such historical evidence, and reliable scenarios were drawn. For each type of hazard, a range of potential effects (danger for humans and assets) has been evaluated in terms of their likely consequence on small settlements (housings) and major infra-structures (road network). Detailed rainfall value compilation for a period of 82 years (1920-2002) has been done to evaluate the critical range of rainfall volumes (cumulative rainfall depth; rainfall inten- 
sity; both recognized on historical basis as threshold values, able to set in motion portions of slopes) that lead to instability and trigger slope failures. Analytical hydrological models (Kirpich and Fréchet formulae) have been used to simulate flood waves and to model (Flo 2D software) debris flow magnitude, outflow direction and depositional extent in the flood-affected built-up areas due to debris flow. This allows better estimation and quantification of the expected effects. To identify the optimum methodology we have ensured the reliability of our systematic search, collection, selection and critical validation of existing data and documentation. Different kinds of documents (mainly technical reports arose from different archival sources) were compared in between and checked on-site for their reliability. Special care has been taken to collect existing material, to normalize data appropriately in view of necessary cartographic transposition and to choose a meaningful map scale $(1: 5000)$. In terms of geology and geomorphology the studies by AEM (Hydro-Electric Power Supply Agency of Turin, which manages hydro-electric power plants in the Orco Valley) have been followed. Also the "technical annexes" (i.e. the geomorphological studies, descriptions and maps draft by practitioners) of the Piano Regolatore Generale Comunale (PRGC) related to the town-planning within communes have been used for this work. The approval and subsequent adoption of the PRGC by Communal Administrations constitutes an official and responsible realization of the natural hazards posed by slope instabilities throughout the region. It also represents an acknowledgement of the hazard classes and inherent restrictions imposed by recent rules, especially after the disastrous flooding events of 1993 and 2000. The intrinsic limit for such annexes is the scale $(1: 10000)$ and built-up area centre, not the whole region.

The hazard damage database has been generated from old and recent bibliographic sources, newspaper articles, pictures (e.g. Fig. 3), unpublished documents of CNR-IRPI and several public archives, including communes of the Orco Valley and from the online archives of Regione Piemonte. A systematic attempt has been made to examine the historical evidence of instabilities (largely from field and aerial photographs) and to verify numerous descriptions of ancient slope failures (many of which date back to the middle of the 17th century). It includes old nomenclature of stream channels that might have changed in morphology and description of protection works (Fig. 2). To analyse the effects of the events we have exploited the detailed historical research of the CNR-IRPI and other researchers, from documents in national archives, libraries and other public bodies, and correlated them through interviews with local residents and eyewitnesses. A substantial chronology (unpublished) of the events which have produced damaging effects since AD 1030 in the region of the Western Alps (including the Orco Valley) has also been produced. All natural hazard events of the last 40 years have been regularly surveyed and published by the authors. Surveys aimed to find and describe causes, pro-

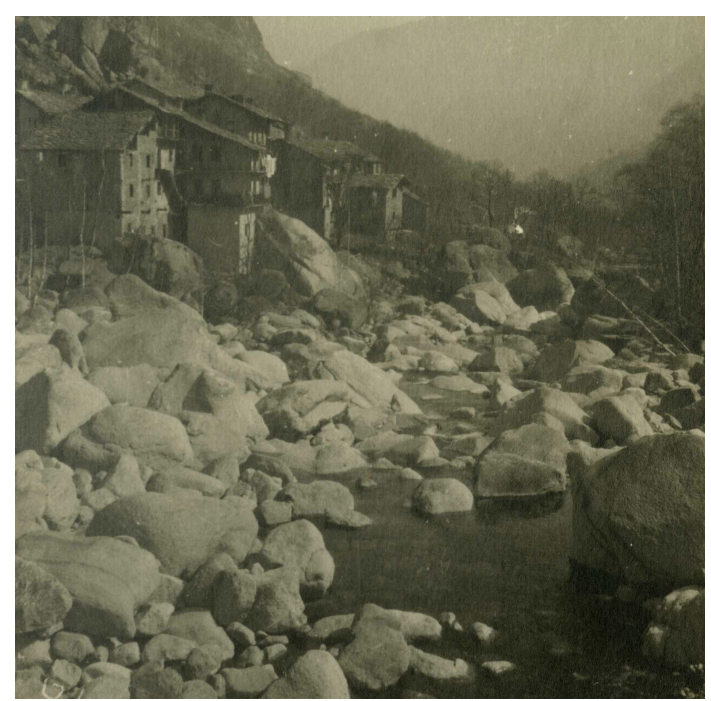

Figure 3. A village in the high Orco basin: very coarse deposits in the main channel as depicted in an old photograph (year 1952).

cesses and effects of landslides, debris flow and flood events and their magnitude in relation to historical events in a given area (Tropeano and Turconi, 2004). On-site measurements for rainfall, discharges and stream flood deposits were complementary in such studies; comprehensive reports were then provided (e.g. Tropeano et al., 1999, 2006).

For preparing land use maps, special attention has been paid to the forest cover, taking the following into account: (1) the key role exerted by vegetation on slope stability conditions and (2) the potential threat of wildfire in the area under study. We have taken help from the unpublished forest maps, drawn by IPLA (Institute for the Study of Trees and Environment) for preparing such map. Specific GIS-based applications have been followed to identify the wildfireprone areas. Weather, wind characteristics, slope aspect, vegetation and elevation have also been considered and combined in an original algorithm.

Field recognition represents a further step towards the integration and testing of information drawn from historical reports, other sources and photo-interpretation. Special attention has been paid to on-site surveys for detailed analysis of geomorphology of the slopes and sub-catchments liable to sudden sediment removal and transport. Recognition of present-day morphodynamic processes in relation to their location and initial conditions has been done with the utmost care. Debris flow source areas have been identified and quantified, in addition to depositional frozen lobes, levees, terraces and paths of previous channel flows on the fan areas. Care has been taken in assessing the contribution of depositional forms to instability processes, either directly by stream activity or by other conditioning causes, which may later lead to failure. Depositional forms recognized in the field have been, in some cases, ascribed to recent processes surveyed 
between 1977 and the present. In some cases older forms have been dated by accurate descriptions in historical documents. In case of inaccessibility field evidence has been correlated with dendro-geomorphological data. The same sampling method has been found useful to define the stratigraphic relationships between depositional sequences along watercourses, and in the timing of debris discharged by slope failures and stream incisions. The torrential deposits caused by extraordinary events of the last 2 centuries have been identified in this way. Old oaks are widespread, allowing the reliable derivation of tree ring ages despite the fact that oaks are less suitable than conifers for this purpose (Bollschweiler and Stoffel, 2009).

Through structural analysis and evaluation of the spatial distribution of rock discontinuities, we have assessed the importance of debris-source areas and preferential routes for the passage of debris flows.

The data layers have been created through transposition at 1:5000 scale of all surface elements, acknowledged by field recognitions, aerial imagery, photointerpretation and documents (geology, geomorphology, land use, gravitydriven processes, debris flow and flood-prone areas, snow avalanches) combined to topographic basis (contour lines, stream network, built-up areas, roads). The work has been conceived as a digital database and a series of map layouts using ArcGIS 9.1. Many surveys could not be completed in whole detail because of inaccessibility at some sites, either through deterioration of tracks and footpaths or because of erosion, rockfall and/or dense vegetation. Attention has been given on the processes potentially affecting settlements (permanently or temporarily occupied), roads, and recreational structures. Morphometric parameters of drainage network have been assessed in order to determine the elements concurring to express the magnitude possible, based on the formula proposed by the authors (Tropeano and Turconi, 2000, 2003) to evaluate the maximum volume of debris and sediments, which should be carried downward in case of paroxysmal events. Such formula is expressed as

$V=(0.542 \mathrm{AE}+0.0151) \cdot 0.019 h \cdot \operatorname{tgs}$,

where $V\left(\mathrm{~m}^{3}\right)$ is the total displaced volume estimated, AE $\left(\mathrm{m}^{2}\right)$ is the effective catchment area, $h(\mathrm{~m})$ is the estimated mean depth (by field assessment) of the removable layer of sediment involved in motion, $\operatorname{tg} s$ is the average catchment slope.

It is generally accepted that a fully vegetated catchment may significantly reduce the likelihood of flooding. It has also been demonstrated, through experiments carried out in the 1980s (e.g. Caroni and Tropeano, 1981), that forest cover acts as an interceptor of prolonged, high-intensity rainfall (i.e. $>10 \mathrm{~mm} \mathrm{~h}^{-1}$ ) and restricts runoff value up to $0.1-$ 0.2 times, in comparison with bare soils. Forest soils can also retain large volumes of shallow groundwater compared to bare or shrub-covered surfaces. Lastly, forest management practices help to ensure that woody debris is not discharged into incised stream channels. Prevention from wildfire being important under this regard (ensuring maintenance of the vegetal cover thus reducing rush waters and soil erosion), the authors also prepared maps showing different aptitudes of the wooded slopes to accidental burnings.

Summarizing, in order to find materials on which a sound technical support to CCP should be based, elaboration of already available multi-source data and documentation, historical studies, photointerpretation and field measurements have been purposely carried out by authors of the present article over the years since 2001. The objective of all these analyses was to find and to furnish useful elements of knowledge to fulfill the CCP. Such bulk of data, vital body of CCP, has greatly improved knowledge in an area where the occurrence of natural hazards is still poorly understood. A further step made by authors was to translate all data and related elaborations in graphical GIS support, as already established procedure (e.g. Turconi et al., 2014). Such efforts mean (a) new insights into the geology, geomorphology, natural processes and event scenarios; and (b) the development of a ready-touse informatics product which allows integration and comparison of significant elements. The output of the natural risk maps is now available on-line and is accessible lexically to the technicians, even those who have very little expertise in applied geology.

\section{Results and discussion}

In the light of new regulations issued by the National and Regional Government on Civil Protection, awareness has been raised towards the fact that Civil Protection should not be limited to the emergency management, but in view of the need for hazard assessment and mitigation should also (a) provide knowledge of the phenomena to which a given area is exposed and (b) deal with the dispersal of information and results. Acquired knowledge on the processes operated in this region must be translated into hazard scenarios. It should, therefore, be specified that the concept of scenario implies a series of evolutionary hypotheses about an active and growing, or potential phenomenon, with increasing damaging effects in the surrounding area of the process. For that reason several (up to three) steps of hazard levels have been stated and translated onto GIS layers (e.g. stream processes). On the basis of the various potential hazards, it is in the opinion of the authors that a further development of research into probabilistic analysis through the timely application of analytical models should be necessary.

From statistical analyses using the landslide inventory, about 60 types of landforms have been detected, with an estimated surface area between 0.05 and $19 \mathrm{~km}^{2}$; the latter value refers to the uninterrupted series of coalescent landslide bodies and constitute the entire right slope of the lower Orco Valley. In the middle reaches of the Orco Valley, two other important collapses have been found on the right and 
left valley slope respectively, i.e. downslope of the Locana village $\left(9.3 \mathrm{~km}^{2}\right)$ and Rosone locality $\left(5.1 \mathrm{~km}^{2}\right)$. A fourth gigantic landslide occupies the left slope of the lower reaches of the Soana Valley (covering ca. $5.9 \mathrm{~km}^{2}$ ). The majority of historical and present-day instabilities involve much smaller volumes and occur in the middle reaches of the Orco Valley; e.g. out of the damaging events reported in the Banca Dati Geologica of the Regione Piemonte, 96 cases occurred between 1628 and 1997 and one-third of these have been involved in torrential activity, while the remainder were involved in slope failures.

A careful, long-lasting search for historical data has been done in public bodies through reading and selection of archival documents (technical relations, manuscripts, maps, etc.), bibliography references and other sources, as explained above. It reveals that natural hazard events (snow avalanches, landslides, rock falls and stream flood) in the Orco and Soana Valleys have occurred at least 480 times over 600 years. Attention has been paid to the interpretation of events affecting the low-order drainage network and tributaries, which have been coded as an inverse function of their recurrence interval, thus expressing the hazard. The exceptional rainfall events, which still affect this area (September 1993, October 2000) indicate that the most hazardous conditions (which may lead to the loss of life) are often related to rapidly or very rapidly evolving processes, rather than stream processes. By "very rapid processes" we refer to rock falls, shallow slides (soil slips) and stony debris flows.

A previous study focusing on stream hazard in the Orco Valley has been widened to include all situations (e.g. valley bottom, alluvial fan), where past channel changes and/or stream overflows have been documented over time. Small tributaries mixed with sedimentary forms, possibly connected to reciprocal flow interchanges, are likely to have occurred in the past, over the alluvial fans or even above the fans themselves. The latter occurrence is more hazardous, as seen recently in the Aosta Valley on October 2000, where six people died (Tropeano and Turconi, 2003). Another source of hazard arises due to the sudden deposition of coarse sediments by minor tributaries that substantially impacts on the flow dynamics by temporary blockage or diversion of the main stream.

One of the thematic maps, drawn from GIS layers cited below, has been prepared to illustrate the stretches of transport networks (roads and footpaths) affected by past, recent and future instability phenomena. Road (or footpath) stretches cover about $72 \mathrm{~km}$; the sources of hazard mainly pertain to low-order streams $(50.2 \%)$ and major streams, using Horton's hierarchical index equal to 4 or above $(47.3 \%)$. Landslide and snow avalanche hazards account for 1.2 and $1.3 \%$, respectively. This relatively low value may be misleading, since after more than 37 years of fairly scarce snowfalls, the winter of 2008-2009 saw huge snowfall on almost all valley slopes to a depth up to above $10 \mathrm{~m}$ at $2296 \mathrm{~m}$ a.s.l. (Arpa Piemonte, 2009). Huge avalanches affected several sites on the main valley road; the largest of these severely disrupted the regional road for a distance of almost $250 \mathrm{~m}$.

Differentiations into the mosaic of physiographic elements (natural and anthropogenic) composing the landscape here concerned led to a logical articulation which required about 90 layers; they have been prepared in the GIS-based inventory (Fig. $4 \mathrm{a}-\mathrm{c}$ ). The slopes close to settled areas of landslide events have been mapped without dividing the initiation, transition and accumulation zones. Four groups of slope instability have been identified, which have been suffixed by "a" or "q", to denote their active or quiescent states respectively:

- rock falls (of both block and coarse detritus);

- deep-seated landslides and/or GSD;

- shallow slides (earth flow, soil-slip);

- "complex" slides, including a wide range of instability processes of different origin (e.g. post-glacial slides) and different kinematic type (rotational-translational, flow, slide) (Figs. 5-8);

- manifold processes inside the incisions, which cannot be discriminated by aerial mapping;

- talus deposits of different origin, with large blocks, and part of glacial deposits, which should be (re)set in motion by complex but not remote start-up conditions.

The term Sackung (Zischinsky, 1969) refers to local subsidence or slope collapse, gravitational expansion or gravitational slope deformation with a deep sliding base (Schwab and Kirk, 2002; Ehret et al., 2005; McCalpin, 2005). Kinematically it is akin to deep creep, i.e. reciprocal or independent displacement by blocks (Brückl and Parotidis, 2005). In terms of dimensions, the most significant slope dynamic processes are the impressive and widespread Sackung and/or GSD, which often affect entire valley sections over a vertical extent of more than a kilometre and over an area usually in excess of a square kilometre (locally in the region of $>5 \mathrm{~km}^{2}$ ). Such failures can reach about $100 \mathrm{~m}$ in depth and tens of millions $\mathrm{m}^{3}$ by volume.

In this context, and recalling what was already said, it is important to explain the concept of "scenario" as an increasing series of evolutionary hypotheses of a given process (active or potential), and to further develop in a degenerative sense the varying stability and safety conditions within a given area.

Previously published studies on this subject agree on the difficulties associated with making accurate forecasts of such events, despite the fact that they are supported by reliable precognitive technologies (such as detailed survey, geognostic and petrographic analysis, monitoring equipment and modelling). On the basis of similar situations in the Orco and Soana Valleys, it seems logical to propose, as an unequivocal 
(a)

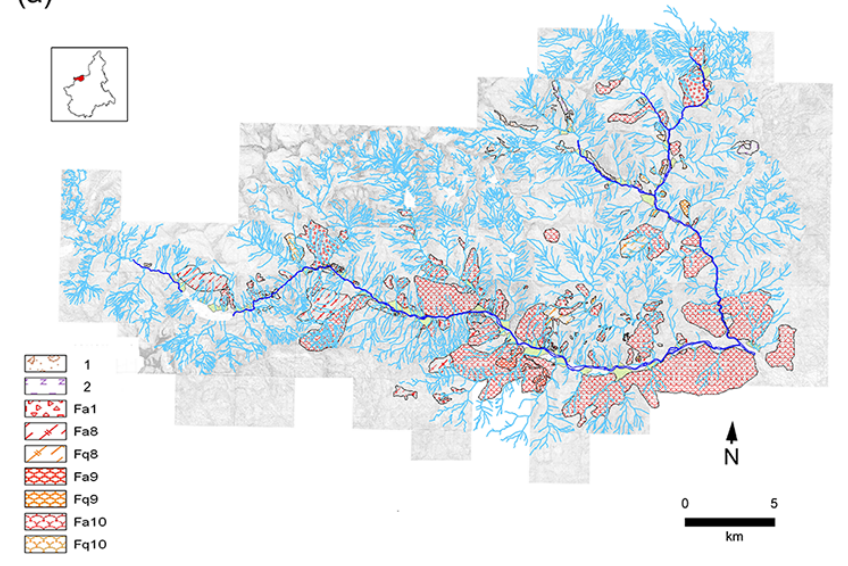

(b)

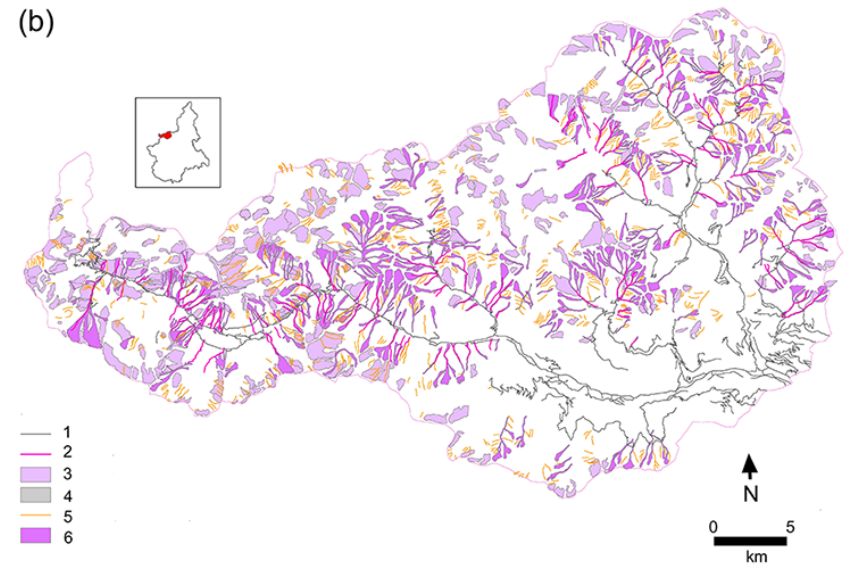

(c)

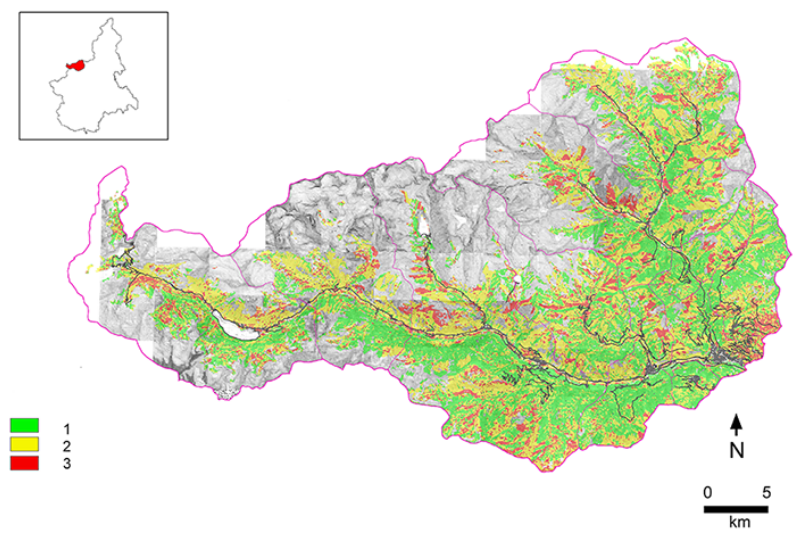

Figure 4. Demonstrative synoptic maps, obtained by a combination of 90 layers at original 1:5000 scale, draft for the CPP of the Orco and Soana valleys. (a) Geomorphological setup. 1: detritus deposits, 2: glacial deposits, Fa1:active rockfall, Fa8: active GSD, Fq8: quiescent GSD, Fa9: recent soil slip, Fq9: historical soil slip, Fa10: active, complex landslide, Fq10: quiescent, composite landslide. (b) Multi-temporal occurrence of snow avalanches. 1: road network, 2: snow avalanche track, 3: slope areas exposed to avalanches, 4: areas provided with protective works, 5: minor avalanches, 6: avalanche-prone impluvia and minor catchments. (c) Wildfire-related risk classes, drawn by a purposely developed algorithm (see Sect. 3), for low, medium and high risk (1, 2, 3, respectively).

evolutionary scenario for such instabilities, the hypothesis of block sliding involves the full valley width and formation of a temporary damming lake. Owing to the difficulty of definition, even with reasonable approximation, of the possible evolutionary phases of such sequential processes, it seems more logical and realistic to define the upper envelope of dormant instability processes, which can be seen in the field or in aerial photographs.

Almost all stream hazards that can be seen here have been mapped for all stream orders from the first order to the main stream flows. Such hazards, principally, range from processes of debris flow to bank erosion, channel overloading (by huge sediment deposition), overflow. The total length of the channel system accounts for $4200 \mathrm{~km}$, which corresponds to an average drainage density of $6.8 \mathrm{~km} \mathrm{~km}^{-2}$. In terms of natural hazards this implies that the efficiency of channel conditions (maintenance without constrictions of full-discharge section) during floods is important, especially when interfering with man-made structures (e.g. channel narrowing by bridges, embankments, road walls etc.). Attention was focused on the geometric definition of the morphological units recognized and especially of the sedimentary processes (alluvial fans) through interpretation of the topographic maps at 1:5000 scale (year should be mentioned), and validated through careful examination of stereo-aerial photographs.

For analysing the main streams in the area, the presentday channel has been reconstructed, digitally captured and georeferenced from recent aerial photographs. From the geomorphological map a fairly complex pattern of processes can be seen, from which a simplified map of geomorphologichydraulic hazard has been drawn. This synthesis is a product of the original on-site analysis and of the complex revision and standardization of technical documents provided by Communes under the URP (urban regulating maps or PRGC 


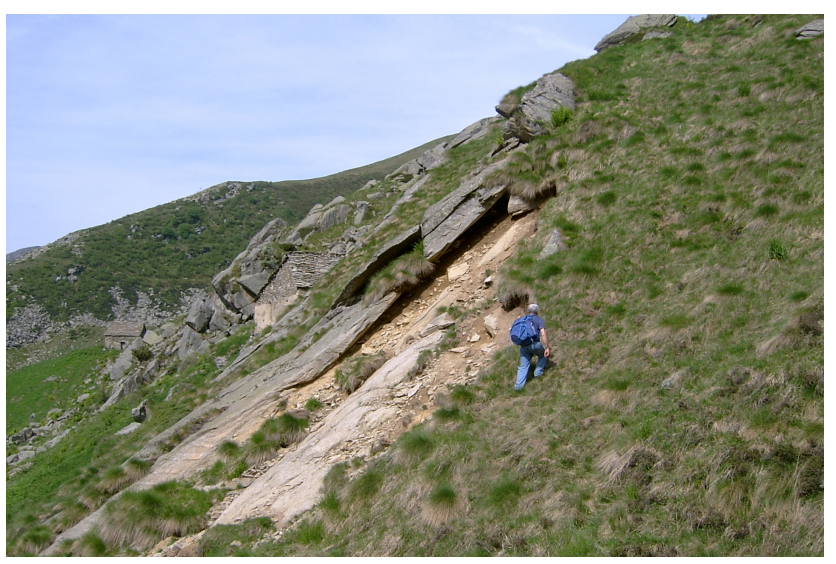

Figure 5. Right slope of a major catchment in the Orco Valley, near the stream head: a rock fall/soil slip process triggered by the extreme rainfall event of October 2000. The matrix-dominated nature of the materials is noteworthy and is connected to weathering products of the bedrock (photo 11 June 2004).

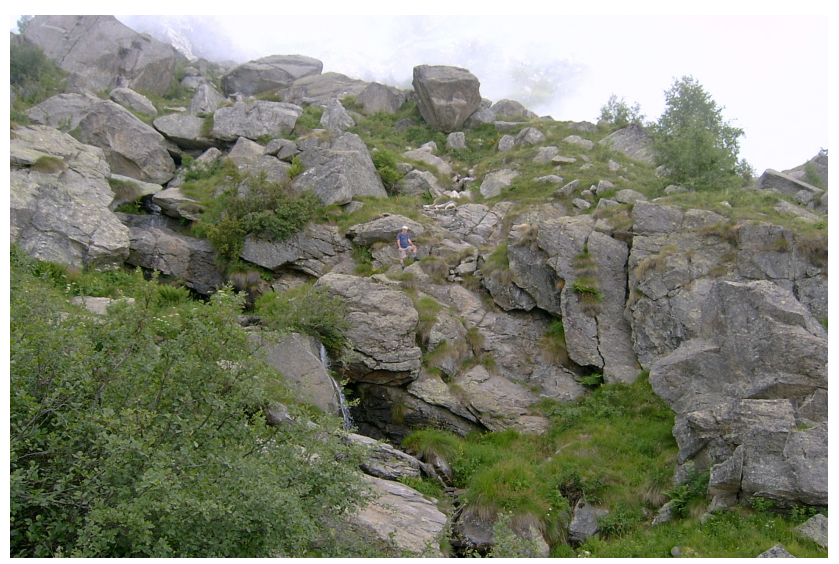

Figure 6. In a steep-sloping sub-catchment in the upper Orco Valley, the right slope, affected by a deep-seated gravitational process, is underlain by disjointed earth blocks and extremely uneven ground surface (photo 12 July 2004).

in Italy). This strategy is necessitated both by current regulations and by the need for a final document acceptable to land administrators. This way, a document which otherwise should be merely useful for bureaucracy and administration has resulted in an "act" of identification and acceptance of the critical nature of situations in the area under consideration. The hazard map focuses and reports on the following elements.

\subsection{Stream hazard}

This has been sub-divided into three classes (TR1, TR2 and TR3) according to their increasing probability of occurrence. Processes involved are channel overdeepening, bank erosion and especially debris flows; an example is provided in Fig. 9.

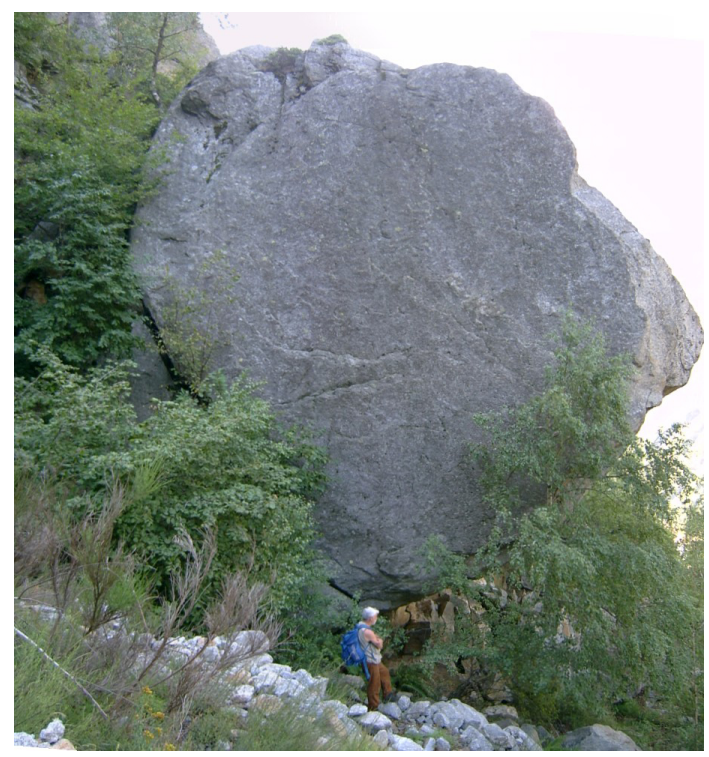

Figure 7. An example of the huge, disjointed stony blocks outcropping on the left slope of the Orco Valley, behind a settled area a few hundred metres downslope (photo 21 July 2004).

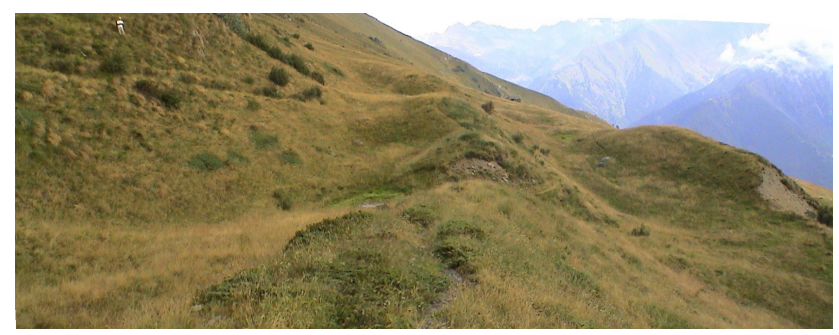

Figure 8. Watershed of tributary of the Soana stream, incised in a deep-seated slope collapse deposit; typical features include trenches and counterslope surfaces, often with emergent water (photo 31 July 2003).

TR1 represents a conservative delineation, based on topographic and geomorphologic criteria, from contour lines of a strip of land close to the channel courses, which has a high probability of lateral erosion, deposit widening and channel deepening. Such a strip is established for homogeneity in a zone of a few tens of metres wide on both banks of the stream. The width of this zone is in some cases overestimated for the easiness of reading, but it may also be underestimated where channels are poorly incised and in the intermediate and lower stretches of the channel network. Such zones have conventionally been defined, by geomorphological and topographic criteria, as the length as far as the fan apex the present-day preferential flow direction is also outlined on each fan.

TR2 is a pejorative class, drawn from interpolation between the flow path directions in the fan areas that can be acknowledged as elongated depressions radiating from the fan apex; such interpolation should result in the delineation 


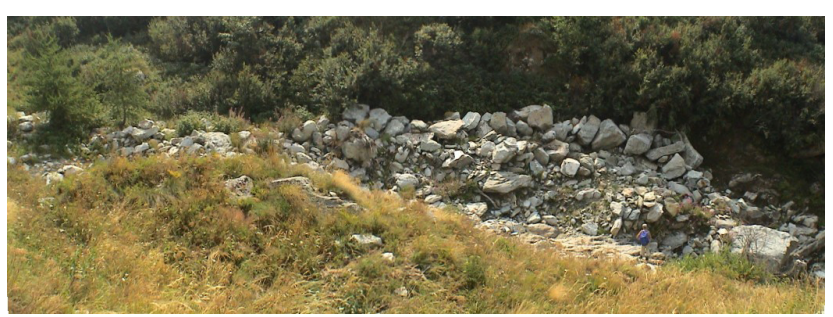

Figure 9. Residual deposit of a debris flow (October 2000), which shows typical inverse gradation, along a left tributary of the Soana stream (photo 8 August 2003).

of an area which is still below the largest event magnitude expected.

TR3 represents the whole fan area. There is a fairly good probability that in case of a paroxysmal flood or abnormally huge debris flow, the physical invasion area of flows in extreme conditions should invade the whole fan surface. In the absence of specific simulation models (fitted to each catchment scale and characteristics, and based on suitably validated entry parameters) to corroborate such a hypothesis, we refer to this extreme class.

\subsection{Flood hazard}

This refers to flood dynamics in valley bottoms and two classes are identified (FR1 and FR2) in reference to the expected flood occurrence; (a) flood hazard assessment is simply based on geomorphological criteria, and (b) on direct field survey and stereo aerial photo-interpretation. FR1 roughly corresponds to the present-day channels in the main drainage network, while FR2 refers to a large inundation area. FR2 is drawn by the interpolation (when data are available) between extreme limits of the valley bottom expansion, as dramatically illustrated by the heaviest flooding surveyed by the authors in 1993 and 2000. This area was deduced by geo-morphological photo-interpretation of detailed aerial imagery.

\subsection{Landslide hazard}

The slope failures shown in the geomorphologic map (described in Sect. 4) have been grouped into two large classes (LR1 and LR2) reflecting the failure mechanism and the different hazard types caused in settled areas (in terms of intensity and rate of evolution). In the LR1 class (higher hazard) we have grouped rockfall, earth flow, soil slip, combined channelized processes, debris talus and unstable glacial deposits. Ninety-nine debris masses of potential instability have been detected, extending over the whole area of over $19 \mathrm{~km}^{2}$. In the LR2 class we have grouped deep-seated landslides and complex slides, combining 65 detrital bodies with a total area of $85 \mathrm{~km}^{2}$. The value above does not refer to the whole basin area, but only to slope instability processes in proximity to settled areas or those directly interacting with settled areas.
The triggering factor of stream floods and most landslides are considered here as exceptional rainfall events. This may sound vague but it is accepted that, in general, such a definition applies to meteorological and hydrological events which cause damaging effects on the landscape.

Our research finds that events of a given magnitude and process may recur periodically in the same localities and with the same physical behaviour and points to long-term instability. The most important variable is the colonization by humans, the effects of which may result in increasing potential damage or hazard. Back-analyses to accompany the maps illustrated here are intended to be both descriptive of past events and predictive of future hazard occurrences.

\section{Conclusions}

Joining together several sources found in the course of the study (bibliography, unpublished reports, old manuscripts, etc.) the authors have acquired historic knowledge on past hazardous events and related damages in the Orco and Soana valleys. The most striking result is that, due to the severe hazardous processes, many lives have been lost in the area: at least 250 deaths have been recorded since 18th century, in the occasion of 36 different dates/processes events. Snowavalanche victims account for $59 \%$, victims of stream floods account for $21 \%$; debris flows and rock falls account for 12 and $8 \%$ of deadly events, respectively.

The CPP should be viewed as the framework of a generic procedure of substantiated up-to-date predictions, on the basis of geographical, geomorphological and historical knowledge of past events (Tropeano and Turconi, 2004). This work represents the first attempt of an overview of the physiographic characteristics of the whole valley system incorporating and interfacing the safety conditions of slopes and streams with anthropogenic activities. The scope of the CPP may be limited, in that it cannot be relied upon to provide categorical prevention measures (which may be obtained only through far-sighted urban policy), but it allows very useful conclusions to be drawn on the variable susceptibility of different land units of sudden and catastrophic events. No reliable results arose from comparison between rainfall data series and possible magnitude of the hazardous events (specifically shallow slides, soil slips and debris flows) in predicting their occurrence by evenly distributed rainstorms, being too scattered over the territory rainfall records of historical significance. Concerning the most recent extreme flood events (1993 and 2000) covering largely distributed areas in the area under study, we can roughly say that they were generated by threshold rainfall amounts equal to or greater than $500 \mathrm{~mm}$ in the antecedent 4 days and for hourly rain intensity equal to or greater than $20 \mathrm{~mm}$. 
This work allows a detailed classification of the entire area (at a scale of 1:5000) as a function of the historical hazard conditions of any locality and time and verified present-day natural and anthropogenic conditions. Fieldwork has been involved in the exploration of archives and eye-witness accounts, and the progress of this work has been discussed and explained, step by step, with local communities and groups (stakeholders). As a consequence, the end-product of this work, i.e. the CPP, represents a unique collaborative effort between authors, administrators and local residents; few examples of such kind elsewhere in the Alps are reported (e.g. Gamper, 2008; Ribitsch and Hermann, 2009).

Many research topics remain to be developed, especially those concerning (a) the time period during which natural events of a given intensity may recur, and (b) the improvement of techniques and knowledge, at the highest possible detail and in relation to anthropogenic activities. Finally, in social terms, we find that the residents of such changeable and potentially hazardous mountain environments should be made fully aware of the hazards, since they have to live with them in order to make optimum use of the land.

Acknowledgements. The authors are grateful to the editor Thomas Glade, and the learned reviewers for their valuable comments and for upgrading the paper.

Edited by: T. Glade

Reviewed by: two anonymous referees

\section{References}

Arpa Piemonte - Agenzia Regionale per l'Ambiente: Rendiconto nivometrico stagione invernale 2008-2009, http://www.arpa.piemonte.it/upload/dd/Servizi_online/

Rendiconti_nivometrici/rendiconto_nivo2008-09_parte1_2.pdf (last access: 18 January 2010), 2009.

Bollschweiler, M. and Stoffel, M.: Jahrringe und Naturgefahren. Wie und wo können Bäume bei der Gefahrenbeurteilung helfen?, Wildbach- und Lawinenverbau, 73, 40-52, 2009.

Brückl, E. and Parotidis, M.: Prediction of slope instabilities due to deep-seated gravitational creep, Nat. Hazards Earth Syst. Sci., 5, 155-172, doi:10.5194/nhess-5-155-2005, 2005.

Caroni, E. and Tropeano, D.: Rate of erosion processes on experimental areas in the Marchiazza basin (northwestern Italy), International Symposium on "Erosion and sediment transport measurement”, 22-25 June 1981, Florence, International Association of Hydrological Sciences, IAHS Press, Wallingford, UK, 457466, 1981.
Ehret, D., Rohn, J., and Moser, M.: Grossräumige Massenbewegungen in der Weltkulturerberegion Hallstatt-Dachstein (Oberösterreich), Tagung für Ingenieurgeologie Erlangen, Nuremberg, Germany, 1-6, 2005.

Gamper, C. D.: The political economy of public participation in natural hazard decisions - a theoretical review and an exemplary case of the decision framework of Austrian hazard zone mapping, Nat. Hazards Earth Syst. Sci., 8, 233-241, doi:10.5194/nhess-8233-2008, 2008.

Malaroda, R.: Geomorphology and neotectonics of the Valle Sacra in the Alto Canavese (Western Alps, Piedmont, Italy): an explanatory note to the Carta geomorfologica e neotettonica della Valle Sacra (1:12.500), Geografia Fisica e Dinamica Quaternaria, 27, 131-138, 2004.

McCalpin, J.: Gravitational Spreading (sackung) studies at GEOHAZ, http://www.geohaz.com/GravSpread4.htm (last access: 21 March 2006), 2005.

Mercalli, L. and Cat Berro, D.: Climi, acque e ghiacciai tra Gran Paradiso e Canavese, Collana 'Memorie dell' Atmosfera' (4), Società Meteorologica Subalpina, Graficat, Torino, Italy, 1-755, 2005.

Ribitsch, R. and Hermann, S.: Georisikokartierungen im Rahmen der Gefahrenzonenplanung - Beispiele aus der Gemeinde Gasen, Oststeiermark, Wildbach- und Lawinenverbau, 73, 72-82, 2009.

Schwab, J. W. and Kirk, M.: Sackungen on a Forested Slope, Kitnayakwa River, Extension Note No. 47, Forest Sciences Prince Rupert Forest Region, Ministry of Forests, British Columbia, Cananda, 1-6, 2002.

Tropeano, D. and Turconi, L.: Predictability of the mass transport of sediments in alpine catchments, The case study of $\mathrm{T}$. Thuras (NW Italy), Internationales Symposion Interpraevent 2000, Villach, Osterreich, 321-333, 2000.

Tropeano, D. and Turconi, L.: Geomorphic classification of alpine catchments for debris-flow hazard reduction, Debris-Flow Hazards Mitigation: Mechanics, Prediction and Assessment, 10 12 September 2003, Davos, Millpress, Rotterdam, 1221-1232, 2003.

Tropeano, D. and Turconi, L.: Using historical documents in landslide, debris flow and stream flood prevention. Applications in Northern Italy, Nat. Hazards, 31, 663-679, 2004.

Tropeano, D., Govi, M., Mortara, G., Turitto, O., Sorzana, P., Negrini, G., and Arattano, M.: Eventi alluvionali e frane nell' Italia Settentrionale. Periodo 1975-1981, Pubbl. n. 1927, CNR IRPIGNDCI, L'Artistica, Savigliano, Italy, 1-279, 1999.

Tropeano, D., Luino, F., and Turconi, L.: Eventi di piena e frana in Italia Settentrionale nel periodo 2002-2004, Pubbl. N. 2911, CNR IRPI-GNDCI, Società Meteorologica Subalpina, Bussoleno, Italy, 2006.

Turconi, L., Nigrelli, G., and Conte, R.: Historical datum as a basis for a new GIS application to support civil protection services in NW Italy, Comput. Geosci., 66, 13-19, doi:10.1016/j.cageo.2013.12.008, 2014.

Zischinsky, Ü.: Über Sackungen, Rock Mech., 1, 30-52, 1969. 